\title{
EL DERECHO PENAL COMO INSTRUMENTO DE LOS MEDIOS DE COMUNICACIÓN PARA CONTROLAR A LA SOCIEDAD
}

\section{THE CRIMINAL LAW AS AN INSTRUMENT OF THE MEDIA TO CONTROL SOCIETY}

\author{
Rodrigo Portillo Acosta ${ }^{1}$ \\ Abogado \\ Universidad de San Martín de Porres \\ rodrigoportillo.91@gmail.com
}

Perú

\section{SUMARIO}

- Introducción

- ¿La realidad social se construye?

- ¿Y cómo los medios construyen la realidad?

- El discurso mediático sobre la cuestión criminal

- La criminología mediática y sus implicancias en la criminalización primaria

- La fabricación del estereotipo criminal por los medios de comunicación

- El miedo: una estrategia útil para controlarnos

- Conclusiones

- Referencias

\section{RESUMEN}

La legislación penal en toda nuestra región toma un tinte absolutamente represivo frente a los problemas reales; se cree que a través de leyes y agravamiento de penas se resolverán los problemas, naturalmente no resuelven nada, es decir, se muestra la incapacidad del estamento político para resolver conflictos, dando la sensación de resolverlos. Todo esto impulsado por los medios masivos de comunicación social (criminología mediática) que construyen la cuestión criminal mediante discursos vindicativos, represivos, estereotipos criminales y repetición sistemática de noticias violentas, mostrando como únicos riesgos sociales los homicidios y delitos comunes, ocultando otro tipo de peligros reales que amenazan a la población. Esto trae como consecuencia el pánico moral en la sociedad y la aceptación de controles policiales.

\begin{abstract}
What criminal legislation is doing throughout our region is to take an absolutely repressive tinge, with a total ineffectiveness against real problems; It simply sells illusions that through laws and aggravation of penalties the problems are solved, it naturally does not solve anything. They are witnessing a new idolatry, due to the inability of the political establishment to resolve conflicts, which do not care to solve them, but to sell the impression or feeling that they are solved, all this driven by the mass media (Mediatic criminology), which construct the criminal issue through vindictive, repressive speeches, criminal stereotypes and systematic repetition of violent news, showing only social risks, homicides and common crimes, hiding other real dangers that threaten the population, causing Moral panic in society and the acceptance of police controls.
\end{abstract}

\section{PALABRAS CLAVE}

Punición, criminalización, criminología mediática.

\section{KEYWORDS}

Punishment, criminalization, media criminology.

1 Miembro del Centro de Estudios en Criminología de la Facultad de Derecho de la USMP. 


\section{INTRODUCCIÓN}

En el Perú hay una tendencia entre los ciudadanos a sentir que el crimen se está incrementando. «En el 2010, solo el $12 \%$ de los encuestados por LAPOP percibía la inseguridad como el problema más importante del país» (diario El Comercio, 2015). En el 2014 esta cifra aumentó a 47 \% (Barómetro de las Américas, 2014).

Hace unos años, un exministro del Interior del Perú expresó, mediáticamente, que en el país no había violencia real, sino solo sensación de inseguridad. Estas declaraciones ocasionaron un linchamiento mediático contra el ministro. Los periodistas decían a los televidentes: ¿Cómo que no hay delincuencia? Vemos todos los días noticias sobre diversos crímenes que suceden en el país.

Desde ese momento, quedó casi prohibido hablar sobre la sensación de inseguridad, porque para los medios de comunicación no existe sensación de inseguridad, sino crímenes reales. Sin embargo, ambos tienen razón, porque sí existe sensación de violencia y también, violencia real, pero son dos fenómenos distintos.

A decir verdad, no es que las personas experimenten constantemente un contacto directo con la violencia criminal, la mayor parte de televidentes se entera por lo que dicen los medios de comunicación, porque es imposible estar en todos los lugares donde suceden hechos violentos. Por ello, se dice que la comunicación es el acto de construir la realidad.

De este modo, los medios cumplen un rol muy importante en la opinión pública y esto se ve reflejado en los pensamientos del televidente sobre la criminalidad gracias a la información que recibimos día a día sobre estos hechos. Por ejemplo:

Prendemos la televisión y observamos una ola de crímenes: han dejado una granada en la puerta de un colegio, han matado a directores de planteles educativos, han matado a alguien para robarle el celular y así la lista continúa.

En esa misma línea, si no transmiten esa clase de noticias, pasan programas de persecución policiaca, series de criminales o juicios y castigos a delincuentes. Así, este tema se vuelve parte de la cotidianidad, y es un tema infaltable en las reuniones familiares, en las conversaciones con los amigos, en la universidad, en la oficina, en las plazas, entre otros.

Entonces, las personas toman medidas de seguridad para protegerse, en muchos casos, es preferible no salir de casa, mudarse, comprar alarmas de seguridad, cercos eléctricos, entre otras medidas. Pero «no todo lo que nos dicen los medios de comunicación es cierto», porque las personas conocen la cuestión criminal con base en lo que dicen los medios de comunicación. Ellos nos dicen cuántos crímenes tenemos, quiénes son delincuentes, cómo roban, dónde paran, cómo hay que cuidarnos y nos explican basándose en prejuicios, estereotipos, causalidades mágicas, y eso es lo que la gente cree como en la mitología de las cavernas de Platón, en un mundo de sombras. Esto es lo que se denomina criminología mediática y que explicaremos a continuación.

¿Pero qué es en sí la criminología mediática? El profesor (Zaffaroni, E, 2011) explica lo siguiente:

La criminología mediática es la creación de la realidad a través de información, subinformación y desinformación en convergencia con prejuicios y creencias basada en una etiología criminal simplista asentada en la "causalidad mágica. Aclaremos que lo mágico no es la venganza, sino la idea de una causalidad canalizada contra determinados grupos humanos, que en términos de la tesis de René Girard se convierten en chivos expiatorios. (p.2)

Hay una diferencia entre la criminología mediática y la criminología académica: la primera se aplica en las universidades mediante trabajos de investigación y la segunda la construyen los medios de comunicación, condicionando tanto el comportamiento de los políticos, como de la población en general.

Los políticos para ganar votos y obtener popularidad repetirán el discurso de la criminología mediática, el cual señala que la punición y represión social son la solución a los conflictos sociales. Esto crea una falsa idolatría o falso dios, que es el derecho penal, como instrumento que va a solucionar todos nuestros males, y como toda religión, tiene sus seguidores y fanáticos. 


\section{¿LA REALIDAD SOCIAL SE CONSTRUYE?}

Sin duda, la obra fundacional del constructivismo social en lo relativo a la comunicación de masas es el conocido libro de Berger y Luckman: La construcción social de la realidad (1983).

En esa obra explican que la realidad social se construye de diversas maneras, por ejemplo: con el conocimiento, con el tiempo, con el lenguaje, en la intersubjetividad, en las relaciones de las personas, entre otras. Así, hay diversas realidades sociales, pero la real por excelencia es cotidiana, ya que esta se encuentra en el espacio en el cual nos desenvolvemos día a día.

Así, la realidad social, entendida como el conjunto de prácticas y tipificaciones que hacen posible la interacción entre los sujetos y que, a la vez, se funda sobre ella, es producto de los propios procesos sociales en que participan los diferentes actores (Aguado, 2004, p. 193).

\section{¿Y CÓMO LOS MEDIOS CONSTRUYEN LA REALIDAD SOCIAL?}

Mediante la información, en ese sentido, Giovanni Sartori (1998) dice que: «Informar es proporcionar noticias. La información da solamente nociones. Lo cual no es negativo. También el llamado saber nocional contribuye a la formación del homo sapiens. Pero si el saber nocional no es de despreciar, tampoco debemos sobrevalorarlo. Acumular nociones, repito, no significa entenderlas» (pp. 45).

Asimismo, Bourdieu y Sartori coinciden que: «Lo que podemos ver en la televisión es lo que "mueve" los sentimientos y las emociones: asesinatos, violencia, disparos, arrestos, protestas, lamentos; y en otro orden de cosas están los terremotos, incendios, aluviones y varios incidentes» (Sartori, 1998, p. 84).

Foucault afirmaba que desde 1830 en todos los países del mundo se desarrollaron campañas sobre el tema del crecimiento de la delincuencia, hecho que nunca ha sido probado, pero esta supuesta presencia, esta amenaza, ese crecimiento de la delincuencia es un factor de aceptación de los controles. Si nos ponemos a pensar que desde 1830 la delincuencia está creciendo, probablemente casi todos estaríamos muertos.
Por otro lado, Becker, en el libro Outsider, citó un estudio muy interesante sobre las noticias policiales en los periódicos del estado de Colorado, elaborado por James Davis, quien investigó que el número de delitos reportados por los periódicos locales no tenía relación con los cambios reales en los índices de la delincuencia de aquel Estado. Además, la estimación de la gente con respecto al aumento de la delincuencia en Colorado respondía al aumento del número de noticias policiales y no al incremento real del delito (Davis, 1952).

\section{EL DISCURSO MEDIÁTICO SOBRE LA CUESTIÓN CRIMINAL}

En un reciente trabajo de investigación, se analizaron los tres diarios más leídos en el Perú: Ojo, Trome y El Comercio. Este sondeo se delimitó en el periodo 2011-2014 y arrojó que del $100 \%$ del universo de noticias criminales que se muestran en las portadas: el $50 \%$ del diario Ojo correspondían a noticias de homicidio y el $14 \%$ al delito común. Luego, el diario Trome presentó un $62 \%$ de homicidios y $22 \%$ de delito común. Por último, el diario El Comercio mostró un $40 \%$ de portadas sobre homicidios y $14 \%$ de delitos comunes. (Portillo, 2016).

De esta forma se expone que los homicidios en conjunto con el delito común son los más difundidos en los medios, construyéndolos como únicos riesgos sociales. Sin embargo, las cifras de homicidios en el Perú son relativamente bajas.

La tasa de homicidios en el Perú es de 6,6 por cada cien mil habitantes: Perú es el sexto país con menor tasa de homicidios en América (INEI, 2015). Este bombardeo de noticias violentas hace pensar en el imaginario social que si uno abre la puerta de su casa, va a encontrar una alfombra de muertos.

Estos delitos violentos se muestran con un discurso vindicativo que evidencian un mensaje de venganza, solicitando pena de muerte para criminales, aumento de penas, castigos severos $\mathrm{y}$ un mayor poder punitivo.

Si nos ubicamos por un momento bajo la lógica de la criminología mediática, supongamos que colocamos a los criminales en la plaza pública, si se quiere, los torturamos y luego los ejecutamos como en la Edad Media... y 
¿la víctima? ¿Quién revive a la víctima? La criminología mediática subestima cualquier programa de prevención de la violencia.

Estas noticias violentas nos ocultan otros tipos de noticias que los medios no informan. Un ejemplo práctico es que aún no sabemos exactamente qué pasó con el derrame de petróleo que causó la empresa PetroPerú en el río del alto Marañón (Amazonas) desde marzo del 2016. ¿Acaso eso no es un crimen casi irreversible? ¿No es un crimen la degradación del planeta que ocasionan las talas de árboles, la contaminación de las minerías ilegales? ¿No es un crimen que malos funcionarios se roben las arcas del Estado? ¿No existen crímenes de cuello blanco y corbata? ¿No es un crimen la trata de mujeres y niñas en los campamentos mineros de Madre de Dios (selva peruana) para explotarlas sexualmente? Son crímenes invisibles.

Los medios seleccionan los hechos que van a informar $\mathrm{y}$, los que tengan los insumos necesarios para despertar sensaciones y emociones en el público, se convertirán en noticia. Estas noticias seleccionadas formarán parte de la opinión pública como la agenda setting. Las demás no interesan, porque no tenemos contacto con otras realidades sociales.

En el trabajo de campo, hallamos un discurso que casi siempre utilizan los medios: «Ola de crímenes». Por un lado, cuando señalamos «discurso», nos referimos a la construcción social de la verdad, quien lo crea o lo impone, en este caso es el poder mediático. Pero no son ola de crímenes reales, son crímenes bajo una creación de la realidad desproporcionada con la realidad objetiva. Esto instala un mundo paranoico entre los habitantes. El $90 \%$ de los peruanos teme ser víctima de un delito.

Este temor responde a que los medios se dedican a atender los intereses financieros de las grandes corporaciones y transnacionales, los cuales forman parte del entramado económico. Buscan abarcar masivamente el mercado, y ¿cómo lo consiguen? Con noticias violentas, porque venden.

Se puede comprobar, porque si uno abre la página de un periódico, encuentra una noticia de una persona muerta; pasas la página y hay una chica en bikini vendiéndote un producto.

Es el neocolonialismo en la fase superior, compuesto por las corporaciones, quienes toman el poder, ya no se invaden territorios, ahora se coloniza el pensamiento, te distraen, y crean nuevas necesidades (Zaffaroni, 2015).

En ese sentido, (Nietzsche, 1985) decía que no existe un solo hecho, sino diversas interpretaciones, y cada medio de comunicación va interpretar un hecho de acuerdo con los intereses económicos de las grandes transnacionales y corporaciones. Por eso, cada medio cuenta el mismo hecho desde diferentes ángulos.

\section{LA CRIMINOLOGÍA MEDIÁTICA, Y SUS IMPLICANCIAS EN LA CRIMINALIZACIÓN PRIMARIA}

La criminología mediática también se condiciona en la criminalización primaria. En el rastreo de las noticias criminales en el Perú, del 2011 al 2014, se evidenciaron datos importantes como la promulgación de tres nuevos delitos por la influencia de los medios de comunicación (Portillo, 2016).

Citaremos los casos:

Primero. En el 2011 los medios comenzaron a informar mediáticamente sobre diversos homicidios contra mujeres en la ciudad; sobre esto se pronunciaban políticos, ministros, periodistas, y algunos congresistas como la exlegisladora María Cuculiza, quien fue una de las promotoras de la promulgación de la Ley del Feminicidio.

«El país con más alto índice [sic] de muertes de mujeres es el Perú» (Luisa María Cuculiza, congresista de la República, Frecuencia Latina, 2011). Eso dijo la congresista.

Asimismo, por el discurso empleado de los medios, daba la sensación que habría un incremento de este fenómeno.

De esta manera, en el 2013, se promulgó la Ley del Feminicidio. Lo interesante de esta presión mediática y la creación de este nuevo delito es que en realidad no había un incremento de feminicidios, los datos oficiales arrojaban una cifra baja, casi como las de Francia, la cual se mantiene casi constante.

La pregunta es ¿cuáles son los elementos metodológicos que utilizan los medios para determinar que teníamos una «ola de 
feminicidios»? No me refiero a los datos o comprobación del dato porque existen, sino para la producción de una organización sistemática que permita un discurso organizado sobre un tipo de situación, acontecimiento o hecho

La Organización Mundial de la Salud estableció la violencia como un problema de salud pública. ¿Cómo se establece? En los homicidios, cuando un país sobrepasa las 10 víctimas por cada 100 mil habitantes, se considera una epidemia de homicidios, por tanto, se convierte en una ola.

Las cifras estadísticas de los feminicidios del 2014 arrojaban 84 víctimas. Partimos de que toda muerte es lamentable, así sea una o mil, pero esa cifra hay que convertirla a tasa para saber si tenemos una epidemia, ¿y cómo se hace? Se divide 84 entre 30 millones de habitantes por 100 mil y el resultado arroja casi 1 por cada 100 mil habitantes, casi las mismas tasas europeas.

Esta práctica mediática fue utilizada para crear la Ley de Sicariato, es más, dicho tipo penal no existía en el Código Penal y los medios ya calificaban la mayoría de homicidios como sicariato, como ocurrió en el 2014. En el 2015 se promulgó la ley. Recordemos que la tasa de homicidios en Perú es relativamente baja.

Asimismo, otra noticia empezó a generar un impacto en la sociedad: los acosos sexuales callejeros; esto se mediatizó aún más con la actriz de televisión, Magaly Solier, quien fue víctima de un hecho que atentaba contra la moral y las buenas costumbres: un sujeto se masturbó dentro del Metropolitano, mientras miraba a la actriz. Esta noticia tenía los insumos necesarios, como el sexual, para despertar el morbo.

El hecho trascendió a los medios y la coyuntura se prestó a que canales de televisión y periódicos difundieran, seleccionaran e informaran estos hechos. En el 2015 se promulgó la Ley del Acoso Sexual Callejero.

Como se puede analizar, la relación del tiempo en difundir estas noticias con la criminalización de los legisladores son muy estrechas, lo que permite inferir que la presión mediática coloca en la agenda legislativa qué tipos penales deben de crearse.

Y la respuesta rápida por parte del Estado, y la única solución más inmediata que simbólicamente genere una tranquilidad en la sociedad, es el incremento de la pena.

\section{LA FABRICACIÓN DEL ESTEREOTIPO CRIMINAL POR LOS MEDIOS DE COMUNICACIÓN}

El principal enemigo de los medios son los jóvenes de barrios precarios. El que viste gorrita y bermudas anchas, y habla de una manera achorada. Ellos son los chivos expiatorios.

Zaffaroni (2011) nos dice:

El mensaje es que el adolescente de un barrio precario que fuma marihuana o toma cerveza en una esquina, mañana hará lo mismo que el parecido que mató a una anciana a la salida de un banco. Por ende, hay que separar de la sociedad a todos ellos y si es posible eliminarlos (p.3).

Construyendo socialmente este estereotipo criminal como el responsable de todos los fenómenos criminales a las clases menos poderosas y menos ilustradas, estigmatizándose y etiquetándolos como si todos fueran delincuentes.

En ese sentido, cualquier persona que se asemeje a este prototipo y cumpla con las características físicas será más proclive de ser seleccionado por el poder punitivo como autor de un crimen. Estas explicaciones simplistas de los medios provienen de las teorías criminológicas positivistas, cuyo precursor fue César Lombroso, quien se basaba en la fisonomía del individuo como la etiología de la criminalidad.

Este es un discurso totalmente discriminatorio y racista. No hay un prototipo criminal, cualquier persona puede cometer un crimen: los de barrios precarios, como los de clase económica alta, o clase media; y no me refiero solo al homicidio o robo, sino también al crimen como todo hecho que transgrede las normas sociales para maximizar los beneficios y perjudicar a terceros, vulnerando derechos.

Este prejuicio influye en las personas, porque cuando alguien observa este estereotipo dice: ¡Cuidado! Ese tiene cara de choro. Sin embargo, este estereotipo no encaja con un funcionario corrupto. 
Al Estado resulta útil que le temamos al crimen. Recordemos que en la fase superior del neocolonialismo se practican dos cosas:

\section{Se coloniza el pensamiento.}

2. En los países donde hay un gran índice de homicidios, se los normaliza y los que tienen índices bajos se amplifican. ¿Por qué?

Con respecto al primero, el neocolonialismo ya no mata para colonizar, pero se normalizan los homicidios, porque permiten que se maten entre ellos. El gran número de víctimas por un homicidio doloso pertenece a estratos sociales bajos y el victimario también pertenece a ese mismo estrato social. Este es el llamado genocidio por goteo.

Y en los países donde hay un bajo índice de violencia, se amplifican para crear una sociedad de riesgo.

El mercado mundial, nos señala el profesor Zaffaroni. (2015), está compuesto por un $30 \%$ de incluidos, y un $70 \%$ de excluidos. Ese $70 \%$ se tiene que controlar. ¿Cómo? Con el miedo.

\section{EL MIEDO: UNA ESTRATEGIA ÚTIL PARA CONTROLARNOS}

Controlan nuestra libertad, nos crean una necesidad de protección. Por ello, el Estado tiene que protegernos de «ellos» los malos. Permitimos que el Estado utilice distintas tecnologías primitivas y sofisticadas para brindarnos seguridad; es decir, pedimos que nos vigilen de «ellos» dotando las calles de más policías, serenazgos y militares; instalando cámaras de vigilancia; entre otros. Lo que se busca en realidad es controlarnos y nosotros autorizamos ese control por el miedo de ser víctima de un delito, que es creado por la criminología mediática.

\section{CONCLUSIONES Y RECOMENDACIONES}

\section{Conclusiones}

Los medios de comunicación construyen socialmente el fenómeno de la criminalidad mediante discursos vindicativos, represivos, estereotipos criminales y repetición sistemática de noticias violentas, mostrando como único riesgo social: los homicidios y el delito común, ocultando otros tipos de peligros reales que amenazan a la población, sintetizando la realidad del Perú como un país caótico y violento.

Existe una relación inversamente proporcional entre los crímenes violentos que difunden los medios de comunicación y la realidad criminal.

Las implicaciones de la criminología mediática en las personas son el elevado índice de sensación de inseguridad y pánico moral.

La presión mediática conllevó a que se promulguen leyes penales innecesarias en el Perú como la Ley de Feminicidio (2013), la Ley de Sicariato (2015) y la Ley de Acoso Sexual Callejero, (2015). Todas con una relación cercana al tiempo de la cobertura mediática. Estas normativas penales no redujeron los niveles de victimización; sin embargo, han ocasionado un hacinamiento de $120 \%$ sobre la capacidad de los establecimientos.

\section{Recomendaciones}

Esnecesariaunacriminologíacautelarymilitante, en la cual la sociedad civil se pronuncie cuando haya cualquier descontrol punitivo, difusión desproporcionada y sistemática de noticias violentas en los medios, discursos vindicativos, discursos represivos, discriminación mediante estereotipos criminales, promulgación de leyes penales innecesarias y otros generados por la criminología mediática.

Como dice el profesor Zaffaroni (2015): «La sociedad civil y el Estado deben de contribuir a despertar a nuestras poblaciones del letargo televisivo, erigirse en un freno al actual genocidio por goteo, romper los paradigmas que hay sobre criminalidad, asegurar los derechos elementales de los habitantes, jugarse decididamente por el modelo de sociedad inclusiva y, para todo eso, otorgar prioridad doctrinaria y jurisprudencial al derecho, al desarrollo humano, íntimamente relacionado con el derecho a la vida individual y colectiva de la humanidad en el planeta».

\section{REFERENCIAS}

\section{Fuentes bibliográficas}

Berger, P. y Luckmann, T. (2003). La construcción social de la realidad. Buenos Aires, Argentina: Cultura Libre. 
Bourdieu, P. (1997). Sobre la televisión. Barcelona. España: Anagrama Barcelona.

Foucault, M. (1976). Las Redes de Poder. Conferencia pronunciada en 1976 en Brasil. En: Barbarie, N. ${ }^{\circ} 4$ y 5) San Salvador de Bahía, Brasil.

Foucault, M. (2009) Vigilar y castigar (2. ${ }^{\mathrm{a}}$ ed.). Buenos Aires: Siglo XXI. .

Moreno, A. (2013). «Descripción y fases del mecanismo del chivo expiatorio en la teoría mimética de René Girard». En: ENDOXA. Series Filosóficas, N. ${ }^{\circ}$ 32, 2013, pp. 191-206. UNED, Madrid.

Sartori, G. (1998). Homo videns. La sociedad teledirigida. Buenos Aires, Argentina: Aguilar, Altea, Taurus, Alfaguara, SA.

Taufic, C. (2008). Periodismo y lucha de clases. Chile: AKAL.

Winfried, H. y Muñoz, F. (2012). Introducción a la criminología y a la política criminal. Valencia: Tirant lo Blanch.

Zaffaroni, R. (2011). La cuestión criminal. En: Suplemento Especial de Página 12. Recuperado de http://www.pagina12.com. ar/especiales/archivo/zaffaroni_cuestion criminal/1-8.la_cuestion_criminal.pdf

\section{Fuentes electrónicas}

Acevedo, J. (2014). Medios de comunicación en el Perú. XII Segundo Congreso Latinoamericano de Investigadores de la Comunicación. Lima, Perú. Pontificia Universidad Católica del Perú. Recuperado de http://congreso.pucp.edu.pe/alaic2014/ medios-de-comunicacion-en-el-peru/

Aguado, J. (2004). Introducción a las teorías de la comunicación y la información. Murcia, España: Universidad de Murcia. Recuperado de http://www.um.es/tic/Txtguia/ Introduccion $\% 20 \mathrm{a} \% 201 \mathrm{as} \% 20$ Teorias $\% 20$ de \% 201a\%20Informa\%20(20)/TIC\%20 texto $\% 20$ guia $\% 20$ completo.pdf

Clases de Periodismo.com (agosto de 2013). Perú: diario Trome es el tabloide más vendido del mundo. Recuperado de http://www. clasesdeperiodismo.com/2013/08/14/perudiario-trome-es-el-tabloide-mas-vendido-delmundo/
Hikal, W. (2008). La criminología latinoamericana y sus figuras representativas. Recuperado de http://www.leliobragacalhau. com.br/la-criminologia-latinoamericana-ysus-figuras-representativas/

Huamán, F. y Becerra, C. (2014). Debate sobre la concentración de medios en el Perú: el caso de la fusión del grupo El Comercio con el grupo Epensa. GT18: Ética, libertad de expresión y Derecho a la Comunicación. Recuperado de http://congreso.pucp.edu.pe/alaic2014/wpcontent/uploads/2013/11/vGT18-HuamanBecerra.pdf

Instituto Nacional de Estadística e Informática (INEI) (2015). Tasa de homicidios en el Perú es de 6,74 víctimas por cada 100 cien mil habitantes. Recuperado de https://www.inei. gob.pe/prensa/noticias/tasa-de-homicidios-enel-peru-es-de-674-victimas-por-cada-100-milhabitantes-8665/

Instituto Nacional de Estadística Penitenciaria (2015). Informe estadístico penitenciario. Recuperado de http://www.inpe.gob.pe/pdf/ junio_2015.pdf

Lagos, Marta y Dammert, Lucía (2012). La seguridad ciudadana. El problema principal de América Latina. Latinobarómetro Recuperado de http://www.latinobarometro. org/documentos/LATBD_La_seguridad_ ciudadana.pdf

Latinobarómetro (2014). Cultura política de la democracia en Perú y en las Américas, 2014: gobernabilidad democrática a través de 10 años del Barómetro de las Américas. Recuperado de

http://www.vanderbilt.edu/lapop/peru/ AB2014_Peru_Resumen_Ejecutivo_ Final_W_042215.pdf

López, E. (1996). «Agenda-setting: investigaciones sobre el primero y el segundo nivel». En: Communication \& Society, $9(1 \mathrm{y}$ 2). Recuperado de http:/www.unav.es/fcom/ communication-society/es/articulo.php?art_ $\mathrm{id}=286$

Ministerio de Justicia y Derechos Humanos (2014). Política nacional frente a los delitos patrimoniales. Consejo Nacional de Política Criminal. Recuperado de http://www.minjus. gob.pe/wp-content/uploads/2014/07/pndp.pdf 
Paponi, M. (2004). «La subjetividad bajo nuevas formas de control». Themata, revista de filosofía. Número 33, pp. 305-308. Recuperado de http://institucional.us.es/ revistas/themata/33/31\%20paponi.pdf

Pontificia Universidad Católica del Perú (septiembre de 2013). Informe Puntoedu: debate sobre la concentración de medios. Recuperado de http://puntoedu.pucp.edu.pe/ noticias/informe-concentracion-de-medios/

Ramos, C. (1995). "Los medios de comunicación, agentes constructores de lo real». En Comunicar 5. pp. 108-112. Recuperado de http://rabida.uhu.es/dspace/ bitstream/handle/10272/736/b 15346109. pdf?sequence $=1$

Ríos, G. (2016). «El lado poco conocido de la globalización en la grave afectación a los derechos humanos: un enfoque criminológico para prevenir y reducir la criminalidad organizada a nivel mundial». Revista Inclusiones. Homenaje a Eugenio Raúl Saffaroni 3 (2), pp. 206-227. Recuperado de http://www.revistainclusiones.cl/articulos/vol3-num-abril-junio-2016/11-oficial-vol-3-num2-abr-jun-2016-dr.-gino-rios---patio.pdf

Rocha, J. (2006). «Los medios de comunicación y la construcción de la realidad». En Hoja de Ruta. (4. . edición). Consultado el 9 de junio de 2016. Recuperado de http://www.hojaderuta. org/ver_articulos.php?id_texto $=90 \&$ id revista $=\overline{14}$
Secada, P. (27 de abril de 2015). «Inseguridad desplazó a la economía como mayor problema del país». En El Comercio (página web). Recuperado de http://elcomercio.pe/politica/ gobierno/inseguridad-desplazo-economiacomo-mayor-problema-pais-noticia-1806962

Sistemas Nacionales de Cultura (sin fecha). Medios de Comunicación y Cultura. Recuperado de http://www.oei.es/cultura2/ peru/07.htm

USAID del Pueblo de los Estados Unidos de América (2014). Cultura política de la democracia en Perú y en las Américas, 2014: Gobernabilidad democrática a través de 10 años del Barómetro de las Américas. Recuperado de http://www.vanderbilt.edu/ lapop/peru/AB2014_Peru_Country_Report Final_W_042215.pdf

Zaffaroni, E. (2015). «El derecho latinoamericano en la fase superior del colonialismo». Passagens: Revista Internacional de Historia Política e Cultura Jurídica Río de Janeiro, 7(2), pp. 182-243. Recuperado de http:// perso.unifr.ch/derechopenal/assets/files/ articulos/a_20150908_03.pdf 